\title{
Análisis de la remisión tributaria y su impacto en la recaudación de impuestos en el Ecuador, periodo 2018
}

Fecha de recepción: 2021-11-03 • Fecha de aceptación:2022-01-03 • Fecha de publicación: 2022-02-10

Esthela Vaneza Otavalo Cacuango

Universidad Central del Ecuador

vane_chikitta@hotmail.com

https://orcid.org/0000-0002-8514-1915

\section{RESUMEN}

Los impuestos constituyen un recurso económico para poder cubrir el gasto público de un Estado. Por otro lado, la recaudación de impuestos se ve afectada por el incumplimiento de las obligaciones tributarias por parte de los contribuyentes, que, debido a ciertos factores, no realizan su pago a tiempo. Este problema acarrea que el SRI (Servicio de Rentas Internas) no recaude de manera efectiva los recursos económicos, en este sentido, el Estado se ve en la necesidad de expedir leyes que permitan una recaudación ágil y a corto plazo de recursos, como lo es una remisión tributaria. El presente trabajo es un análisis de la remisión tributaria en el Ecuador aplicado en el año 2018, en donde se logró gestionar una recaudación de 1.268 millones en total, lo que corresponde a 351 mil contribuyentes beneficiados. Este análisis se fundamenta en la investigación documental y analítica de la información proporcionada por el SRI, así como la revisión pormenoriza de manuscritos relacionados al tema de investigación, lo que ayudará a determinar el impacto generado en la recaudación de impuestos por la aplicación de este tipo de régimen, qué sectores se beneficiaron de su aplicación, así como si este tipo de leyes son favorables para el Estado. 


\section{ABSTRACT}

Taxes are an economic resource to cover the public expenditure of a State. On the other hand, tax collection is affected by the non-compliance of tax obligations by taxpayers who, due to certain factors, do not pay their taxes on time. This problem means that the IRS (Internal Revenue Service) does not effectively collect economic resources, in this sense, the State has the need to issue laws that allow an agile and short-term collection of resources, such as a tax remission. The present work is an analysis of the tax remission in Ecuador applied in 2018, where a total collection of 1,268 million was managed, which corresponds to 351 thousand taxpayers benefited. This analysis is based on documentary and analytical research of the information provided by the SRI, as well as the detailed review of manuscripts related to the research topic, which will help determine the impact generated in tax collection by the application of this type of regime, which sectors benefited from its application, as well as whether this type of laws are favorable for the State. 


\section{Introducción}

Los ingresos tributarios constituyen una fuente de recursos importante dentro de la instauración del presupuesto general del Estado, estos permitirán cumplir con los deberes primordiales de la nación en los ámbitos de educación, salud, alimentación y seguridad social (Asamblea Nacional del Ecuador, 2008).

El Servicio de Rentas Internas (SRI) constituye el órgano rector encargado de efectuar la determinación, recaudación y control de los tributos internos del Estado, según lo establecido en la Asamblea Nacional del Ecuador (2017).

La recaudación de dichos ingresos (tributos) se realizará mediante la aplicación de leyes y políticas, que le permitan cumplir con las metas establecidas dentro del ejercicio fiscal. Por otro lado, cada contribuyente está en la obligación de cumplir con sus deberes como sujeto pasivo del tributo, presentando a tiempo sus declaraciones tributarias; sin embargo, existen factores que no fomentan este cumplimiento y provocan el retrasado continuo de las obligaciones tributarias, sea esto por desconocimiento de la ley, desconfianza en la redistribución de los ingresos o por evasión tributaria. Según Urdaneta et al. (2020), "la informalidad, el deficiente control tributario y el bajo desarrollo financiero tienen implicaciones negativas en el cumplimiento tributario en empresas pequeñas y medianas, como el aumento de la evasión y elusión fiscal. Términos que difieren la una de la otra; pero, en sí tienen la misma finalidad "reducir el pago de impuestos" (p. 146).

Este incumplimiento genera sanciones, multas e intereses que aumentan con el transcurso del tiempo, generando una acumulación de valores pendientes de pago por parte del contribuyente, lo que promueve una cartera pendiente de cobro por parte de la Administración Tributaria, afectando directamente a la recaudación de los recursos. El SRI presentaba un saldo en cartera firme antes de la remisión tributaria del año 2018 de 2.709 millones USD y posteriormente este saldo fue de 2.500 millones USD, lo que permite determinar que la aplicación de este tipo de leyes promueve el ingreso de recursos de manera eficaz.

En el 2018, el estado ecuatoriano promulgó la Ley Orgánica para el Fomento Productivo, en la cual se evidencia en su capítulo I el Régimen de remisiones y reducciones, enfocado al ámbito tributario y cuya aplicación se traduce a la condonación de intereses, multas y recargos de las obligaciones tributarias que mantenía los contribuyentes en deuda hasta el pasado 2 de abril de 2018.

De este modo, es preciso mencionar que la obligación tributaria se define, según Durán (2013), como "el núcleo central de la relación jurídica compleja que surge entre el ente público acreedor del crédito tributario y el particular, sujeto pasivo de esa relación” (p. 11). Mientras que de acuerdo con el Código Tributario (Asamblea Nacional del Ecuador, 2005), "es el vínculo existente entre los contribuyentes, sujeto pasivo del pago del tributo y el Estado responsable de la recaudación; la cual se puede extinguir: mediante solución o pago, compensación, confusión, remisión y prescripción de la acción de cobro" (p. 5). 
Dada como una forma de extinción de la obligación tributaria, la remisión o amnistía está enmarcada en la legislación tributaria y corresponde a la condonación de las deudas tributarias en virtud de la ley, en la cuantía y con los requisitos que en la misma se determinen.

Su análisis es de gran interés, ya que nos permite conocer la cantidad de contribuyentes que se acogieron a este régimen, y que, según cifras proporcionadas por el SRI, ascienden a 351 mil contribuyentes beneficiados; así como determinar cuáles fueron los sectores económicos que se favorecieron y examinar los montos que la administración tributaria recaudó bajo esta amnistía, permitiendo de este modo el ingreso de recursos a las arcas del Estado. Se dará a conocer las veces que ha existido este tipo de remisiones tributarias en el Ecuador y cuán importante es poder obtener recursos a corto plazo, reduciendo costos indirectos al contribuyente y también permitiendo una optimización de los recursos administrativos, tecnológicos, legales y de otra índole a la Administración tributaria; además la presente investigación tiene como objetivo determinar si este tipo de regímenes contribuyen a mejorar la cultura tributaria (Quishpe et al., 2020) de los contribuyentes.

\subsection{La remisión tributaria en el Ecuador}

Es importante hacer énfasis en el término remisión y observar como este se inserta y actúa en el ámbito tributario. La Real Academia Española (2020) lo define como "perdonar, alzar la pena, eximir o liberar de una obligación". En este sentido, dicho término, aplicado en el ámbito tributario, contribuye al perdón de ciertas obligaciones pendientes que tienen los contribuyentes para con el estado.

Dando una definición mucho más amplia y técnica, Figueroa Paladines (2018) menciona que es una de las formas en que se puede extinguir una obligación con el fisco, esta se da de forma unilateral y solo se genera mediante la aprobación de un proyecto de ley el que contendrá los términos y condiciones en las que se ejecutará el perdón o condonación de la deuda (p.15).

De este modo se puede concluir que la remisión tributaria consiste en una forma de extinguir una obligación tributaria, esta se realiza mediante la expedición de una ley en la cual se establecerán todos los parámetros para que los contribuyentes puedan acceder a dicho régimen o beneficio, ella contendrá de manera detallada cuáles son las obligaciones que se condonarán o perdonar, así como los plazos respectivos.

En el Ecuador, en las últimas tres décadas se han llevado a cabo tres importantes remisiones tributarias, Gaibor et al. (2020) las menciona:

- Año 1992: Ley de condonación de intereses adeudados al Banco Nacional de Fomento y Facilitación de pago de obligaciones tributarias. Ley. No. 142 - Registro Oficial No. 878 de 19 de febrero de 1992.

- Año 2008: Ley Orgánica Reformatoria e Interpretativa a la Ley de Régimen Tributario Interno, al Código Tributario, a la Ley Reformatoria para la Equidad Tributaria del Ecuador 
y a la Ley de Régimen del Sector Eléctrico, respecto a la remisión de intereses, multas y recargos. Registro Oficial 392 del 30 de Julio de 2008.

- Año 2015: Ley Orgánica de Remisión de Intereses, Multas y Recargos - Registro Oficial No. 493 de 05 de mayo de 2015.

La recaudación que se obtuvo en el año 2008 representó el 0,24\% del total recaudado en dicho año, el monto recaudado por remisión tributaria fue de 15.388 millones USD correspondiente a 3.124 contribuyentes beneficiados (Mata, 2019).

Mientras que para el año 2015 se recaudó 971.694 millones USD de los que se acogieron 1.107.162 contribuyentes, esto representó el 6,78\% del total recaudado en dicho año (Mata, 2019).

Con estos antecedentes se puede notar que las remisiones tributarias dadas en el Ecuador en los años 2008 y 2015 han tenido acogida por parte de los contribuyentes, si se realiza una comparación entre estos dos años, para el 2015 existe un incremento en recaudación tributaria por remisión de un 63,14\%, existiendo de este modo mayor recursos para el Estado.

Esta línea de tiempo de las remisiones tributarias efectuadas en el Ecuador permite observar que existen maneras óptimas para poder recaudar tributos a contribuyentes que se encuentra pendientes en sus obligaciones tributarias. Mediante la aplicación de este tipo de ley, se le permite al Estado obtener recursos de manera más rápida y eficaz, creando flujos de efectivo a corto plazo y optimizando recursos administrativos, legales y tecnológicos por parte de la administración tributaria.

\subsection{La remisión tributaria en países sudamericanos}

Es importante recalcar cómo se ha aplicado la remisión tributaria a nivel internacional, para poder gestionar recursos económicos de manera inmediata, de este modo en la Tabla 1 se mencionan los siguientes países a nivel de Sudamérica que han aplicado remisiones tributarias.

\section{Tabla 1.}

Principales amnistías realizadas en Sudamérica

\begin{tabular}{ccc}
\hline País & Año & Detalle amnistía \\
\hline Perú & 2013 & Se aplaza y fracciona las deudas contraídas hasta diciembre 2012 \\
\hline Colombia & 2015 & $\begin{array}{r}\text { Se condona del } 50 \% \text { al } 80 \% \text { de los intereses y multas por el pago o la } \\
\text { firma del convenio de pago }\end{array}$ \\
\hline Argentina & 2016 & $\begin{array}{r}\text { Ley de amnistía de capitales no declarados. Permite el blanqueo de } \\
\text { capitales para residentes argentinos (personas físicas y jurídicas) }\end{array}$ \\
\hline Brasil & 2016 & $\begin{array}{r}\text { Ley de repatriación. Trata de regular los recursos y vienen provenientes } \\
\text { de fondos lícitos; aunque no hayan sido declarados. }\end{array}$ \\
\hline
\end{tabular}

Fuente: Vinueza (2021) 
Este tipo de leyes aplicadas en otros países permite analizar que las mismas presiones fiscales para aumentar de forma inmediata la recaudación, en muchas ocasiones también han hecho que se adopten soluciones administrativas de corto plazo. Por ejemplo, en algunos países se han concedido amnistías totales o parciales en lugar de establecer programas de facilidades para el pago de los impuestos morosos (Cetrángolo y Gómez, 2006, p. 147).

Adicionalmente a los países sudamericanos mencionados, existen otros como México, Honduras, Irlanda, España, India, Francia, Bélgica, entre otros, que han optado por implementar medidas de indulto de multas e intereses a las obligaciones tributarias pendientes de pago, gestionando así, con mayor agilidad, la cartera vencida a cargo de cada administración tributaria.

\section{Metodología}

El trabajo de investigación tiene un enfoque descriptivo, lo cual según Hernández et al. (2006), "buscan especificar las propiedades, las características y los perfiles de personas, grupos, comunidades, procesos, objetos o cualquier otro fenómeno que se someta a un análisis. Es decir, miden, evalúan o recolectan datos sobre diversos conceptos (variables), aspectos, dimensiones o componentes del fenómeno a investigar" (p. 102).

En este caso se analizará la remisión tributaria efectuada en el año 2018 bajo la Ley Orgánica para el Fomento Productivo, sus diferentes aspectos e impacto en su aplicación.

El estudio se fundamenta en la investigación documental y analítica, en donde se resalta la información obtenida de fuente primaria del Servicio de Rentas Internas, que mediante sus montos de recaudación dentro del período de remisión 2018 permitirá abordar un estudio pormenorizado de la efectividad en su recaudación. Se abordará la revisión de los datos que se encuentra en su página web, así como los proporcionados de manera directa a través de una solicitud; este último contiene información relacionada a la cantidad de contribuyentes que se acogieron a este régimen, valores recaudados por tipo de contribuyente, grupo de impuesto y actividad económica; y saldo de la cartera antes y después de la remisión tributaria 2018 (Servicio de Rentas Internas, 2018). Pese a que se analizarán valores cuantitativos con respecto a la información que se obtiene de fuente primaria, el enfoque de la investigación realizada es de carácter cualitativo, que de acuerdo con Carhuancho et al. (2019), "se caracteriza por tener básicamente las siguientes características: es descriptiva, inductiva, fenomenológica, holista, sistémica y de diseño flexible. Destaca el análisis y el valor subjetivo de una situación particular".

Así también, se ha tomado en cuenta información de fuente secundaria, lo cual constituyen los artículos y manuscritos elaborados por distintos autores con relación al tema abordado, así como el análisis del impacto de remisión realizada en años anteriores como es el estudio de Reinoso (2015), lo que permitirá analizar y evaluar como su aplicación varía de un período a otro.

En la Tabla 2 se presenta un resumen de la información que será utilizada en el presente trabajo, con su fuente y descripción metodológica.

Tabla 2. 
Base de datos información remisión 2018

\begin{tabular}{ccc}
\hline Base de datos & Fuente & Descripción \\
\hline $\begin{array}{c}\text { Monto de recaudación } \\
\text { por tipo de contribuyente, } \\
\text { actividad económica y tipo } \\
\text { de impuesto }\end{array}$ & SRI & $\begin{array}{c}\text { Estos valores permitirán conocer los montos } \\
\text { recaudados por cada tipo y así se podrá establecer } \\
\text { porcentajes de mayor relevancia. }\end{array}$ \\
\hline $\begin{array}{c}\text { Saldo de la cartera antes } \\
\text { y después de la remisión } \\
\text { tributaria 2018 }\end{array}$ & SRI & $\begin{array}{c}\text { Permitirá identificar la efectividad de la recaudación } \\
\text { realizada. }\end{array}$ \\
\hline $\begin{array}{c}\text { Producto Interno Bruto } \\
\text { Banco Central } \\
\text { del Ecuador }\end{array}$ & $\begin{array}{c}\text { Este indicador permitirá realizar una analogía en } \\
\text { relación a los montos recaudados por actividad } \\
\text { económica y su influencia en el PIB. }\end{array}$ \\
\hline
\end{tabular}

\section{Resultados}

La remisión tributaria del año 2018, establecida por la Ley Orgánica para el Fomento Productivo, Atracción de Inversiones, Generación de Empleo, y Estabilidad y Equilibrio Fiscal, publicada en el Registro Oficial No. 309 del 21 de agosto de 2018, capítulo I, Régimen de Remisiones y Reducciones, tuvo ciertas características para que los contribuyentes puedan acogerse a este régimen, entre ellas se destacan las siguientes:

- Remisión del $100 \%$ de intereses, multas y recargos derivados del saldo de las obligaciones tributarias o fiscales internas bajo la administración del Servicio de Rentas Internas.

- Se aplica a las obligaciones tributarias o fiscales vencidas con anterioridad al 2 de abril de 2018, las obligaciones correspondientes a la declaración anual del impuesto a la renta del ejercicio fiscal 2017, no podrán acogerse a la remisión dictaminada.

- Con relación al plazo de remisión, los contribuyentes que pretendan beneficiarse de la remisión del cien por ciento (100\%) de intereses, multas y recargos derivados de las obligaciones tributarias y cuyo promedio de ingresos brutos de los tres últimos ejercicios fiscales sea mayor a cinco millones de dólares de los Estados Unidos de Norteamérica, deberán efectuar el pago del capital dentro del plazo máximo de 90 días, contados a partir de la publicación de la presente Ley en el Registro Oficial; los demás contribuyentes podrán presentar su solicitud de facilidades de pago hasta un plazo máximo de 2 años o pagar la totalidad del saldo del capital dentro del plazo de 90 días.

- Las personas naturales y sociedades, definidas en los términos del artículo 98 de la Ley de Régimen Tributario Interno, que se acojan en cualquiera de los casos de remisión de intereses, multas y recargos establecidos en la presente ley, no podrán beneficiarse sobre el mismo concepto, a procesos de remisión que se dispongan en el futuro, por un período de al menos diez (10) años.

A continuación, se realizará un análisis de los montos de recaudación que SRI ha obtenido y cómo estos han contribuido al mejoramiento de los recursos económicos del estado. 
La estimación meta de recaudación para la aplicación de este régimen fue de 602 millones; sin embargo, se logró gestionar una recaudación de 1.268 millones en total, de los cuales 1.103 millones corresponden a una recaudación efectiva y 167 millones con facilidades de pago de hasta dos años (2019 - 2020), estas cifras corresponden a 351 mil contribuyentes beneficiados, como se lo ha mencionado en párrafos anteriores.

En el año 2015, según cifras del SRI, la promulgación de la Ley Orgánica de Remisión de Intereses, Multas y Recargos - Registro Oficial No. 493 de 05 de mayo de 2015, produjo una recaudación total de 972 millones, correspondientes a 1.107.162 contribuyentes beneficiados.

Realizando un contraste entre los datos de estos dos años, se evidencia que en el año 2018 se realizó una mayor recaudación, a pesar de que existe un menor número de contribuyentes beneficiados, esta diferencia importante se debe a que en el año 2015 existe un plazo de 60 días para acogerse al $100 \%$ de remisión tributaria, mientras que en la ley promulgada en el año 2018 existe un plazo de 90 días para acogerse a la remisión del 100\%; esta diferencia de días hace que existan una mayor número de contribuyentes beneficiados, y por ende, una mayor recaudación en el último año mencionado.

De los valores efectivos recaudados e informados por la Coordinación Nacional de Previsiones y Estadísticas (2018), se realizarán varios análisis con relación a los montos reportados.

\subsection{Tipo de contribuyentes}

Desde este punto de vista es importante saber que un contribuyente se establece como dos tipos: las personas naturales y las jurídicas, estas últimas se encuentran bajo el control, tanto de la Superintendencia de Bancos, Superintendencia de Compañías y la Superintendencia de Economía Popular y Solidaria; a continuación, se muestra la recaudación tributaria bajo el régimen de remisión de multas y recargos, realizada por tipo de contribuyentes.

Tabla 3.

Recaudación efectiva remisión tributaria año 2018 por tipo de contribuyente

\begin{tabular}{ccc}
\hline \multirow{2}{*}{ Tipo de contribuyente } & Total Recaudado & \multirow{2}{*}{$\%$} \\
\cline { 2 - 3 } & (USD) & \\
\hline PERSONAS NATURALES & $64.139 .153,89$ & $5,81 \%$ \\
\hline SOCIEDADES & $1.038 .901 .278,26$ & $94,19 \%$ \\
\hline TOTALES & $1.103 .040 .432,15$ & $100,00 \%$ \\
\hline
\end{tabular}

Fuente: Servicio de Rentas Internas (2018)

Según la información proporcionada, se infiere que los contribuyentes que más se acogieron a la remisión tributaria del año 2018 fueron las sociedades, lo que representa el 94,19\% del total recaudado efectivo, como se evidencia en la Tabla 3. 
Las sociedades se establecen como los contribuyentes con mayor porcentaje en la recaudación de tributos anual, según datos publicados por el Servicio de Rentas Internas, por ende, es importante que se encuentren al día en sus obligaciones tributarias. Dentro de los tres últimos años anteriores al régimen de remisión tributario, las sociedades o personas jurídicas constituyen más del $80 \%$ en la declaración del impuesto a la renta, uno de los más representativos dentro de la administración tributaria. Los datos se presentan en la Tabla 4.

Tabla 4.

Recaudación Tributaria Impuesto a la Renta del 2015 al 2017

\begin{tabular}{|c|c|c|c|c|c|c|}
\hline \multirow{2}{*}{$\begin{array}{l}\text { DECLARACIONES DE } \\
\text { IMPUESTO A LA RENTA }\end{array}$} & Recaudación & \multirow[t]{2}{*}{$\%$} & \multirow{2}{*}{$\begin{array}{l}\text { Recaudación } \\
\text { Ene-Dic } 2016\end{array}$} & \multirow[t]{2}{*}{$\%$} & Recaudación & \multirow[t]{2}{*}{$\%$} \\
\hline & Ene-Dic 2017 & & & & Ene-Dic 2015 & \\
\hline Personas Naturales & 175.500 & $15 \%$ & 163720 & $15 \%$ & 192348,18 & $10 \%$ \\
\hline Personas Jurídicas & 991.444 & $83 \%$ & 942978 & $84 \%$ & 1655420,9 & $88 \%$ \\
\hline $\begin{array}{c}\text { Herencias, Legados y } \\
\text { Donaciones }\end{array}$ & 25.644 & $2 \%$ & 14530 & $1 \%$ & 28923,105 & $2 \%$ \\
\hline TOTALES & 1.192 .588 & $100 \%$ & 1.121 .228 & $100 \%$ & 1.876 .692 & $100 \%$ \\
\hline
\end{tabular}

Fuente: Servicio de Rentas Internas (s.f)

\subsection{Tipo de impuesto}

En el Ecuador se recauda un sin número de impuestos a personas naturales y sociedades, en la Tabla 5 se muestran los valores recaudados en la remisión tributaria del año 2018, por tipo de impuesto.

Tabla 5.

Recaudación efectiva remisión tributaria año 2018 por tipo de impuesto

\begin{tabular}{lll}
\hline \multicolumn{1}{c}{ Grupo de Impuesto } & \multicolumn{2}{c}{ Total, Recaudado } \\
\cline { 2 - 3 } (USD) & \multicolumn{1}{c}{$\%$} \\
\hline Impuesto a la Renta Global & $897.903 .017,46$ & $81,40 \%$ \\
\hline Impuesto al Valor Agregado & $100.976 .746,61$ & $9,15 \%$ \\
\hline Imp.Ing Extraord. Recur. No Reno & $46.453 .174,50$ & $4,21 \%$ \\
\hline Salida de Divisas & $14.608 .425,63$ & $1,32 \%$ \\
\hline Impuestos Fomento Ambiental & $13.890 .004,59$ & $1,26 \%$ \\
\hline Impuesto a los Vehículos Motorizados & $12.253 .780,33$ & $1,11 \%$ \\
\hline Impuesto a los Consumos Especiales & $7.234 .205,70$ & $0,66 \%$ \\
\hline Otros no Tributarios & $5.720 .719,28$ & $0,52 \%$ \\
\hline Otros Impuestos & $4.000 .358,05$ & $0,36 \%$ \\
\hline TOTALES & $1.103 .040 .432,15$ & $100,00 \%$ \\
\hline
\end{tabular}

Fuente: Servicio de Rentas Internas (2018) 
Con relación a la información proporcionada, se destaca que el impuesto que mejor aceptación tuvo en la remisión del año 2018 es el impuesto a la renta, lo que presenta el $81,40 \%$ de la recaudación total, seguido por el impuesto al valor agregado con el 9,15\% de la recaudación total. Dentro de este contexto es importante mencionar que en los último tres años que preceden al año de remisión tributaria, uno de los impuestos más recaudados a nivel nacional corresponde al impuesto a la renta, en el año 2015 le corresponde el 40,58\% del total recaudado, en el año 2016 el $37,10 \%$ y en el año 2017 el $36,74 \%$.

\subsection{Tipo de actividad económica}

En el país se llevan a cabo actividades económicas que permiten el desarrollo de bienes y servicios en distintos ámbitos productivos, en la siguiente Tabla 6 se muestra cuál fue el sector que se acogió en gran medida a la remisión tributaria.

Tabla 6.

Recaudación efectiva Remisión Tributaria año 2018 por actividad económica

\begin{tabular}{lcc}
\hline \multicolumn{1}{c}{ Actividad económica } & $\begin{array}{c}\text { Total recaudado* } \\
\text { (USD) }\end{array}$ & $\%$ \\
\hline Explotación de minas y canteras. & $482.930 .083,56$ & $43,78 \%$ \\
\hline Transporte y almacenamiento. & $184.058 .576,40$ & $16,69 \%$ \\
\hline $\begin{array}{l}\text { Comercio al por mayor y al por menor; reparación de vehículos } \\
\text { automotores y motocicletas. }\end{array}$ & $113.116 .002,17$ & $10,25 \%$ \\
\hline Industrias manufactureras. & $61.983 .700,75$ & $5,62 \%$ \\
\hline Actividades financieras y de seguros. & $61.301 .216,27$ & $5,56 \%$ \\
\hline Información y comunicación. & $46.325 .852,42$ & $4,20 \%$ \\
\hline Construcción. & $34.025 .029,30$ & $3,08 \%$ \\
\hline Actividades profesionales, científicas y técnicas. & $30.364 .679,90$ & $2,75 \%$ \\
\hline Agricultura, ganadería, silvicultura y pesca. & $24.892 .782,43$ & $2,26 \%$ \\
\hline Sin actividad económica - ciiu & $23.454 .724,63$ & $2,13 \%$ \\
\hline Actividades de servicios administrativos y de apoyo. & $8.266 .854,58$ & $0,75 \%$ \\
\hline Actividades inmobiliarias. & $7.820 .085,84$ & $0,71 \%$ \\
\hline $\begin{array}{l}\text { Otras actividades: atención salud humana, artes, entretenimiento, } \\
\text { alojamiento, administración pública y defensa, enseñanza, bajo } \\
\text { relación de dependencia, distribución agua, otros. }\end{array}$ & $2.450 .0843,90$ & $2,22 \%$ \\
\hline Totales & & \\
\hline
\end{tabular}

Fuente: Servicio de Rentas Internas (2018)

El sector que se acogió a la amnistía tributaria con un mayor porcentaje fue explotación de minas y canteras, con un $43,78 \%$ seguido por la actividad transporte y almacenamiento con un $16,69 \%$.

Los contribuyentes beneficiados son 350 mil, de los cuales el 99.5\% corresponden micro, pequeños y medianos contribuyentes, que según lo establece el Art. 106 del Reglamento a la Estructura de Desarrollo Productivo de Inversión, las microempresas son unidades productivas 
que tienen ventas o ingresos brutos anuales iguales o menores de trescientos mil dólares, las pequeñas de 300.001 a un millón de dólares y las medianas de hasta cinco millones (Gaibor et al., 2020, p. 5).

Este mismo sector (explotación de minas y canteras) dentro del PIB (Producto Interno Bruto) del año 2018, no es un sector representativo, puesto que este se encuentra con un 5,73\% superado por otras industrias; sin embargo, vemos que el sector de manufactura, construcción y comercio constituyen industrias que aportar a la economía del país y estarían ligadas a las siguientes actividades con más recaudación en el SRI por la remisión tributaria como es: transporte y almacenamiento, comercio al por mayor y al por menor; reparación de vehículos automotores y motocicletas e industrias manufactureras.

En la siguiente Tabla 7 se observa lo comentado. 
Tabla 7.

PIB por Industrias año 2018

\begin{tabular}{|c|c|c|}
\hline Industrias & PIB por sector & $\%$ \\
\hline $\begin{array}{l}\text { Manufactura (excepto refinación de } \\
\text { petróleo) }\end{array}$ & $13.778,97$ & $12,81 \%$ \\
\hline Construcción & $12.125,12$ & $11,27 \%$ \\
\hline Comercio & $10.163,51$ & $9,45 \%$ \\
\hline Enseñanza y Servicios sociales y de salud & $9.741,82$ & $9,06 \%$ \\
\hline Agricultura, ganadería, caza y silvicultura & $8.410,78$ & $7,82 \%$ \\
\hline $\begin{array}{l}\text { Actividades profesionales, técnicas y } \\
\text { administrativas }\end{array}$ & $7.818,57$ & $7,27 \%$ \\
\hline OTROS ELEMENTOS DEL PIB & $7.606,06$ & $7,07 \%$ \\
\hline $\begin{array}{l}\text { Administración pública, defensa; planes de } \\
\text { seguridad social obligatoria }\end{array}$ & $7.049,73$ & $6,55 \%$ \\
\hline Otros Servicios (1) & $6.496,05$ & $6,04 \%$ \\
\hline Petróleo y minas & $6.167,43$ & $5,73 \%$ \\
\hline Transporte & $5.534,93$ & $5,15 \%$ \\
\hline Actividades de servicios financieros & $3.688,13$ & $3,43 \%$ \\
\hline Alojamiento y servicios de comida & $2.314,34$ & $2,15 \%$ \\
\hline $\begin{array}{l}\text { Otros sectores: comunicaciones, } \\
\text { electricidad, agua, acuicultura, pesca, pesca } \\
\text { y otros }\end{array}$ & $6.666,56$ & $6,20 \%$ \\
\hline PIB & $107.562,00$ & $100,00 \%$ \\
\hline
\end{tabular}

Fuente: Banco Central del Ecuador (2018)

\subsection{Cartera recuperada}

Un aspecto importante que hay que tomar en cuenta es la cartera que se recuperó con la remisión tributaria del año 2018, antes de la aplicación de este régimen existía un saldo de cartera firme de 2.709 millones USD y un saldo de cartera suspendida de 3.163 millones USD, posteriormente, el Servicio de Rentas Internas reveló un saldo de cartera firme de 2.500 millones USD y de cartera suspendida de 1.170 millones USD. Estas cifras permiten denotar que se recuperó en un 7,72\% la cartera firme y un $63,01 \%$ la cartera suspendida, en donde se comprueba nuevamente que la aplicación de este tipo de estrategias tributarias mejora la recaudación de tributos. No hay que olvidar que en los saldos después de remisión se debe considerar que dentro de la cartera existen 233 millones en facilidades de pago, 191 millones son deuda firme generada durante la remisión y 
87 millones son deuda generada durante la remisión, pero suspendida a espera de resultados de reclamos administrativos o acciones judiciales planteadas por los contribuyentes.

También existió facilidades de pago por 167,17 millones, los mismos que serán recaudados de manera efectiva en los años 2019 y 2020, cabe indicar que esto fue beneficio para contribuyentes micro, pequeño y mediano, a pesar de que en el año 2020 existieron complicaciones a causa de la pandemia no existe indicios que demuestren que los valores como facilidades de pago del año 2020 no se hayan podido cobrar.

Tabla 8.

Impacto al presupuesto general del estado (en miles de dólares)

\begin{tabular}{lc}
\hline \multicolumn{1}{c}{ Recaudación $\mathbf{2 0 1 7}$} & $\mathbf{1 3 . 2 2 4 . 8 9 2}$ \\
\hline Meta de Recaudación 2018 & 14.450 .000 \\
\hline Recaudación 2018 & 15.130 .027 \\
\hline Recaudación Remisión Tributaria 2018 & 1.120 .048 \\
\hline Presupuesto General del Estado 2018 & 34.863 .000 \\
\hline Recaudación 2018 sin Remisión Tributaria & 14.009 .979 \\
\hline Cumplimiento meta de Recaudación 2018 & $104,70 \%$ \\
\hline Variación Nominal Recaudación 2017/2018 & $14,40 \%$ \\
\hline Participación de la Remisión Tributaria 2018 en la Recaudación 2018 & $7,40 \%$ \\
\hline Participación de la Recaudación Tributaria 2018 en el PGE 2018 & $43,40 \%$ \\
\hline Participación de la Remisión Tributaria 2018 en el PGE 2018 & $3,20 \%$ \\
\hline
\end{tabular}

Fuente: Navas et al. (2019)

Según la información que se encuentra en la Tabla 8 se puede evidenciar que existe una participación de la recaudación tributaria del año 2018 en relación al presupuesto general del Estado en un $43,4 \%$, en donde $3,2 \%$ corresponde solo a la participación efectiva de la remisión tributaria. Al existir una variación del 14,4 \% de incremento entre la recaudación del año 2017, frente al año 2018, se concluye que existió una mayor recaudación en el año de aplicación de remisión y esto contribuyó el ingreso de mayores recursos a las arcas del estado.

De acuerdo a los datos suministrados por la administración tributaria, se determina que las remisiones o amnistías tributarias son de gran importancia, ya que esto permitirá generar recursos para el Estado de manera inmediata, minimizando costos en su aplicación tanto administrativos, operativos, tecnológicos como legales. Sin embargo, no hay que olvidar que existieron algunas empresas que son grandes potencias en el Ecuador que no pagaron los intereses y multas respectivas, en relación a sus obligaciones pendientes.

El beneficio de la remisión aplicará para todas las sociedades. La exención será por el 100\% de los intereses, multas y recargos. En el caso de micros, pequeñas y medianas empresas el plazo para acogerse a la remisión será de dos años. Para las grandes, el plazo será de 90 días. El SRI 
calcula que unas 5000 empresas de este segmento se beneficiarán de la medida (El Comercio, 2018).

Los recursos que deja de percibir el estado por la condonación de multas e intereses equivalen al 0,02\% de la recaudación neta del año 2018, este porcentaje no es significativo a nivel macro; sin embargo, son recursos que pudieron ser parte del presupuesto general del Estado y asignados a aspectos importantes dentro del mismo.

USD 4,644 millones era la deuda pendiente de los contribuyentes al SRI (incluyendo capital, intereses por mora, multas y recargos), de los cuales alrededor del 50\% correspondía a multas y recargos que el SRI estaba dispuesto a condonar (USD 2,355 millones) (Franco, 2019).

Es por esta razón que existe gran controversia al momento de aplicar este tipo de régimen tributario, generando una cultura tributaria más débil en donde los contribuyentes prefieren esperar una nueva amnistía tributaria para poder realizar el pago de sus obligaciones que pagarlos a tiempo. Esto se puede notar en la gran cantidad de contribuyentes que se acogieron a esta remisión; pese a esto, hay que tomar en cuenta que, frente a la situación económica cada vez más en declive, estas medidas ayudan generando recursos para que se puedan cumplir con todos los objetivos que tiene para con los ciudadanos. Una medida que permite controlar este tipo de sucesos es establecer un plazo determinado para los que contribuyentes que se acogieron a una remisión tributaria no puedan realizarlo en una subsecuente y de esta manera incentivar a los contribuyentes a permanecer al día con sus obligaciones con el fisco.

\section{Conclusiones}

De acuerdo al análisis realizado en base a los datos proporcionados por el SRI, se concluye que la remisión tributaria establecida mediante ley en el año 2018, permitió la recaudación de 1.268 millones de dólares, teniendo como meta 602 millones, lo que indica que existió gran acogida por parte de los contribuyentes.

Las sociedades fueron los contribuyentes que más se acogieron a este régimen, representando el $94,19 \%$ del total recaudado, lo que permite evidenciar que el poder económico se encuentra en las empresas élite del país.

A su vez, el impuesto a la renta fue el impuesto que tuvo mayor acogida por parte de los contribuyentes, es importante indicar que este ha tenido gran relevancia en los últimos tres años, es un impuesto que genera mayores ingresos de recursos.

Con relación a la cartera vencida en firme, se pudo evidenciar que se recuperó un 7,72\% gracias a la acogida que tuvo la remisión tributaria por parte de los contribuyentes. Adicionalmente, se recalca que existen recursos pendientes de cobro para los años 2019 y 2020, debido a las facilidades de pago que se proporcionaron.

Además, la remisión tributaria ha permitido generar recursos económicos a corto plazo como se ha podido evidenciar en la información analizada; sin embargo, no se puede dejar pasar por 
alto que este tipo de medidas no contribuyen al mejoramiento de la cultura tributaria, si no, todo lo contrario; los contribuyentes pueden adoptar una actitud de indiferencia y no cumplir con sus obligaciones tributarias a tiempo, esperando que una próxima remisión les permita estar al día con sus obligaciones tributarias.

Finalmente, es importante recalcar que existe un 0,02\% de la recaudación neta del año 2018 que son valores que el Estado dejó de percibir y que, a pesar de no ser montos relativamente significativos, dichos recursos pudieron formar parte del presupuesto general del Estado y cubrir ciertas necesidades importantes en educación, salud u otros; que los ecuatorianos lo exigen. 


\section{Referencias}

Asamblea Nacional del Ecuador. (2005). Código Tributario. Registro Oficial Suplemento Nº 38.

Asamblea Nacional del Ecuador. (2008). Constitución de la República del Ecuador.

Asamblea Nacional del Ecuador. (2017). Ley de Creación del Servicio de Rentas Internas. Última modificación. Registro Oficial 206 de 02-dic-1997.

Banco Central del Ecuador. (2018). Información Estadística Mensual No. 2002 - Diciembre 2018. https://contenido.bce.fin.ec/home1/estadisticas/bolmensual/IEMensual.jsp

Carhuancho, I., Sicheri, L., Nolazco, F., Guerrero, M., \& Casana, K. (2019). Metodología de la investigación holística. UIDE.

Cetrángolo, O., \& Gomez, J. C. (2006). Tributación en América Latina: en busca de una nueva agenda de reformas. Cepal.

Durán, M. (2013). La Obligación Tributaria. Revista Tribûtum, (22), 9-22.

El Comercio. (08 de abril de 2018). 5000 empresas grandes podrán acogerse a la remisión. https://www.elcomercio.com/actualidad/negocios/empresas-remision-sri-ministerio-finanzas.html.

Figueroa Paladines, M. (2018). La remisión como forma de extinción la obligación tributaria, según la normativa ecuatoriana. [Tesis de grado, Universidad Técnica de Machala]. Repositorio Digital de la UTMACH http:// repositorio.utmachala.edu.ec/handle/48000/12811

Franco, G. (14 de octubre de 2019). ¿Es cierto que el gobierno de Moreno perdonó deuda por USD 4,500 millones a los banqueros y a los grandes grupos económicos? Economía en Jeep. https://economiaenjeep.blogspot.com/2019/10/es-cierto-que-el-gobierno-de-moreno.html?fbclid=IwAR3m5Exy-rebHABcwE7 H3kQhQwnU7gdTV3KILff8yNod73P3kAH9pVnm1w\&m=1

Gaibor González, I., Sánchez Fonseca, J., Arias Esparza, J., \& Arguello Mendoza, C. (2020). La Remisión Tributaria 2018 y sus resultados en el Servicio de Rentas Internas Zona 3. mktDESCUBRE, 1(2), 351-358. http://dx.doi.org/10.36779/mktdescubre/v\%23.\%23

Hernández, R., Fernández, C., \& Baptista, P. (2006). Metodología de la Investigación. McGraw Hill Interamericana.

Mata, K. (2019). Impacto de la aplicación de la ley de remisión en el Ecuador en los indicadores de recaudación de los impuestos de la Administración Central, en los años 2008 y 2015, y su Relación con la 
Cultura Tributaria. [Tesis de maestría, Universidad Central del Ecuador]. http://www.dspace.uce.edu.ec/ handle/25000/18867

Navas, G., Jarrín, W., Ramos, G., \& López, A. (2019). La Remisión Tributaria del año 2018 en el Ecuador y su incidencia en el Presupuesto General del Estado. Dilemas contemporáneos: Educación, Política y Valores. https://dilemascontemporaneoseducacionpoliticayvalores.com/index.php/dilemas/article/view/1379

Quishpe, G., Arellano, O., Negrete, O., Rodríguez, E., \& Vélez, K. (2020). La cultura tributaria y su efecto en la evasión fiscal en Ecuador. Revista ESPACIOS,41(29), 153-171. http://asesoresvirtualesalala.revistaespacios.com/a20v41n29/a20v41n29p12.pdf

Real Academia Española. (2020). Remitir. https://dle.rae.es/remitir?m=form

Reinoso Valverde, A. (2015). Análisis del impacto recaudatorio de la Ley Orgánica de remisión de intereses, multas y recargos, período 2008 - 2015. [Tesis de maestría, Instituto de Altos Estudios Nacionales]. http:// repositorio.iaen.edu.ec/handle/24000/5889

Servicio de Rentas Internas. (s.f.). Estadísticas Generales de Recaudación SRI. https://www.sri.gob.ec/estadisticas-generales-de-recaudacion-sri

Servicio de Rentas Internas. (s.f.). Remisión de Intereses, multas y recargos. https://www.sri.gob.ec/remision-de-interes-multas-y-recargos

Servicio de Rentas Internas. (2018.). Remisión Tributaria 2018. Coordinación Nacional de Previsiones y Estadísticas.

Urdaneta, A., Delgado, R., Yanez, M., Quijije, B., \& Cedeño, W. (2020). El cumplimiento tributario y su impacto en el entorno macroeconómico de la competitividad empresarial en Ecuador. Revista ESPACIOS, 41(40), 142-156. http://w.revistaespacios.com/a20v41n40/a20v41n40p11.pdf

Vinueza Hidalgo, V. (2021). Impacto de la amnistía tributaria del año 2018 en las finanzas de las compañías anónimas manufactureras del Distrito Metropolitano de Quito, administraciones zonales Eloy Alfaro y Quitumbe. [Tesis de maestría, Universidad Politécnica Salesiana]. http://dspace.ups.edu.ec/handle/123456789/20140 
Copyright (c) 2022 Esthela Vaneza Otavalo Cacuango

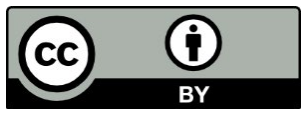

Este texto está protegido bajo una licencia internacional Creative Commons 4.0.

Usted es libre para Compartir-copiar y redistribuir el material en cualquier medio o formato - y Adaptar el documento - remezclar, transformar y crear a partir del material-para cualquier propósito, incluso para fines comerciales, siempre que cumpla las condiciones de Atribución. Usted debe dar crédito a la obra original de manera adecuada, proporcionar un enlace a la licencia, e indicar si se han realizado cambios. Puede hacerlo en cualquier forma razonable, pero no de forma tal que sugiera que tiene el apoyo del licenciante o lo recibe por el uso que hace de la obra.

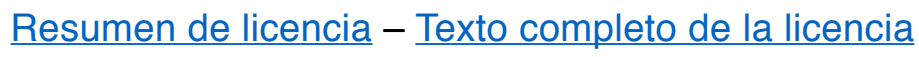

